Article

\title{
Enhancing English-Learning Performance through a Simulation Classroom for EFL Students Using Augmented Reality-A Junior High School Case Study
}

\author{
Yuh-Shihng Chang ${ }^{1}\left(\mathbb{D}\right.$, Chao-Nan Chen ${ }^{2, *}$ and Chia-Ling Liao ${ }^{3}$ \\ 1 Department of Information Management, National Chin-Yi University of Technology, No.57, Sec. 2, \\ Zhongshan Rd., Taiping Dist., Taichung 41170, Taiwan; eric_chang@ncut.edu.tw \\ 2 Department of Computer Science and Information Engineering, Asia University, Taichung 413, Taiwan \\ 3 Lishin Junior High School, 236, Jiati Road, Dali Dist., Taichung 41170, Taiwan; chialingliao10@gmail.com \\ * Correspondence: chencn@asia.edu.tw; Tel.: +886-4-23323456 (ext. 48019)
}

Received: 8 October 2020; Accepted: 4 November 2020; Published: 5 November 2020

check for updates

\begin{abstract}
In non-English-speaking countries, students learning EFL (English as a Foreign Language) without a "real" learning environment mostly shows poor English-learning performance. In order to improve the English-learning effectiveness of EFL students, we propose the use of augmented reality (AR) to support situational classroom learning and conduct teaching experiments for situational English learning. The purpose of this study is to examine whether the learning performance of EFL students can be enhanced using augmented reality within a situational context. The learning performance of the experimental student group is validated by means of the attention, relevance, confidence, and satisfaction (ARCS) model. According to statistical analysis, the experimental teaching method is much more effective than that of the control group (i.e., the traditional teaching method). The learning performance of the experimental group students is obviously enhanced and the feedback of using AR by EFL students is positive. The experimental results reveal that (1) students can concentrate more on the practice of speaking English as a foreign language; (2) the real-life AR scenarios enhanced student confidence in learning English; and (3) applying AR teaching materials in situational context classes can provide near real-life scenarios and improve the learning satisfaction of students.
\end{abstract}

Keywords: augmented reality; AR; EFL students; learning performance; learning motivation; ARCS

\section{Introduction}

Educational programs need to adapt to the context of institutional educational innovation. With global vision and the ability to develop, innovative education is in harmony with the global educational trend. Educational institutions in many European countries have been innovating through the use of advanced digital technologies and educational trends, and have transformed their education programs toward taking the best current approach. In the meantime, student learning performance must be improved without incurring other possible burdens and loads [1].

In regard to junior high and elementary school educational innovation, incorporating digital technology in education has already created a "digital trend"; moving from the traditional way of teaching by using a blackboard and afterward by using a projector to help teaching, the recent trend of teaching in smart classrooms applies computers, smartphones, and other mobile devices to enhance the efficiency and quality of education. By changing from a traditional textbook to digital media technology, a diversity of learning methods can be introduced to students in the digital era $[2,3]$. 
The curiosity and concentration of students can be evoked by applying innovative technologies. That is to say, incorporating digital technology into elementary and junior high school education, using innovative teaching methods, such as playing games to enhance student interest and learning performance, can make teaching more interesting [4]. In particular, applying augmented reality (AR) in educational contexts has become more and more popular, as it provides an interactive learning experience. It also allows for embedding artificial computer-generated artefacts throughout the "real world," thus allowing students to experience learning content in the real world, rather than through a 2D-based system [5].

Regarding previous research on applying technology for language learning, Shadiev and Yang [6] focused on language-learning design and teaching activities. A total of 398 research papers from 2014 to 2019 have been reviewed, in which the most discussed were related to English-learning effectiveness. Considering 23 diverse technologies, including computer, network, and digital technologies, among others, games (49) and videos (37) were primarily taken for study [6]. With respect to language learning, they also mentioned that incorporating innovative technologies such as virtual reality, augmented reality, or wearable technology into the design of situational context education has been widely popularized and discussed [6,7]. Based on these papers, Golonka et al. [8] also demonstrated the effectiveness and validity of applying technology to language learning and teaching. While innovative technology has made a huge impact on language learning and teaching, other studies (e.g., pronunciation training-related research) have also supported the technology [8].

In order to speak English as a second language in Taiwan, students start to learn English in elementary school; however, even after going to university, most people still cannot communicate with foreigners who use English, in terms of both listening and speaking. It is difficult for students to learn English in non-English-speaking countries (i.e., EFL). When there is no "real" learning environment in EFL countries, traditional teaching methods may limit students' learning potential [9-11]. Thus, AR technology has been considered as the best solution for such learning issues. By using a smartphone or tablet, a student can have a one-to-one interactive conversation learning experience in the simulated context [12]. Hsu [13] found that using AR in the real world can effectively support students to achieve situational learning and help reach their goals. AR, as a tool to develop ubiquitous learning guidance systems for EFL learners, can help to speed up their reaction time in language learning [14]. Findings have indicated a positive result of AR enhancing student learning performance [6]. Based on AR technology, Hsu [13] developed two learning systems, in which students can learn English vocabulary in a top-down text environment. The results showed that AR tech can facilitate ubiquitous learning, that the student may perceive a sense of existence and realism, and that learning motivation can also be enhanced. Thus, AR can allow for the innovation of educational methods. Worldwide, educational institutions and educators have been concerned with how to effectively apply AR digital technologies to certain subjects and educational aspects, as well as how to properly and objectively evaluate the learning performance of students using digital technologies to learn. Because of the popularity of smart mobile devices, incorporating foreign language teaching applications into the smartphone context provides a feasible method for education, the learning effectiveness of which has been increasingly researched [15].

According to the GSMA (Groupe Speciale Mobile Association), there are 3.6 billion smartphone users in the world, which means that, in the wireless world, $47 \%$ of the global population are mobile internet users [16]. In 2019, the Taiwan Communication Survey (TCS) also pointed out that each Taiwanese person, on average, uses a smartphone for about three hours per day; furthermore, for users aged 18 to 39, this time can be up to five hours. During this time, some users may use their smartphone as a tool for learning [17]; that is, smartphones have become popular as tools for learning [12] and, for the public, they are likely to adapt smartphones as a learning tool. In articles from 2000 to 2012 related to applying mobile devices to language learning, Duman, Orhon, and Gedik [18] found that, during that period, PDAs were used as tools for learning. The most common related research topic focuses on feedback from elementary school to college students, in terms of the aspects of technology 
and linguistic competence; in which, English learning is the most common topic. Based on EFL-related theses, Hwang et al. [4] proved that mobile technologies can provide environments for students to interact with each other and to collaborate for learning [19,20]. Students can attain a ubiquitous learning environment [12], while the learning context can be designed based on student capabilities and environment [21]. During language learning, the aspects of concentration, interest, and effort may be enhanced by adding entertaining elements into mobile device technologies $[4,20,22]$.

In recent decades, applying digital media technology into mobile devices has been an innovative method for educators. Therefore, the combination of mobile technologies and digital media has become nearly ubiquitous in the language-learning field. Shadiev et al. [7] also pointed out that AR is popular in learning contexts. AR techniques can mix virtual scenes and the real world together, by which an image is therefore created and the resulting hybrid world can provide amazing and interactive phenomena. Because of the popularity of smartphones, they are generally the first choice of consumers to experience AR. For example, Chang, Hu, Chiang, and Lugmayr [5] applied AR techniques to interior design education, which was interesting for students as they could experience the scene ambiance without time delay. According to recent related literature reviews, the value of AR, in terms of positive education feedback and its concentration enhancing function, has been demonstrated $[5,13]$. Folmar [23] considered the power of gamification its ability to produce desirable behavior changes.

Based on above-mentioned statements, it is clear that incorporating AR techniques into mobile device apps can provide effective methods to create a positive EFL learning performance. Thus, in this research, we apply a smartphone English-learning app to situational context classes in order to enhance student's English listening, speaking, reading, and writing abilities. Therefore, we conducted an experiment to examine the learning performance, in which control group students were educated by traditional methods and the experimental group students used a smartphone app as a tool for learning. The results demonstrate the feasibility of applying mobile device AR techniques into education, and that they can effectively enhance English-learning performance. The research subject was junior high school students from the Di-Li district of Taichung City. One of the researchers was the teacher, who carried out the pre- and post-tests during the experimental teaching period, in order to evaluate the aspect of student concentration. Data were collected based on a questionnaire. Finally, by means of statistical analysis, we investigated the differences in learning performance between the two groups of students.

The purposes of this research are (1) to compare the two groups of EFL students, in terms of learning performance and concentration; and (2) to examine whether concentration, confidence, satisfaction, and learning performance were enhanced in the experimental group by use of the AR innovative method. We performed the experiment from the 1st of September, 2019 to the 12th of January, 2020. The experimental results revealed that motivation and learning satisfaction were improved in the experimental students. Applying AR teaching materials for English learning was considered interesting by the experimental group students. Before attempting to answer the above questions, we briefly introduce English-learning-related research in Section 2. After that, Section 3 explains how we implemented the experimental teaching approach and the questionnaire design. Then, in Section 4, the difference between the experimental group and the control group is analyzed through a statistical analysis of the questionnaire feedback. In Section 5, we evaluate the learning effectiveness of experimental group students using the attention, relevance, confidence, and satisfaction (ARCS) model. Finally, we discuss the research results (Section 6) and conclude the research results and limitations (Section 7).

\section{Literature Review}

\subsection{English Learning in the Digital Era}

English is the most widely spoken language in the world. The British Consult report showed that 2 billion people learned English in 2010 and 3 billion people will learn English by 2020 [24]. 
In 2007, Harmer proposed that, among global English speakers, the ratio of native speakers and second language speakers is about 1:2 or 1:3. This ratio is expected to gradually increase over time [24]. The reason that most non-native speakers tend to learn English is they hope to communicate with people who can also speak English, such as students, tourists, or business-people worldwide. Most EFL students learn English in their home countries, where there is no "real" English-speaking environment for them to speak or listen in, which may limit their potential to learn English. Harmer [24] stated two main functions during the process of language learning: (1) message input (i.e., listening and reading) and (2) message output (i.e., speaking and writing). Harmer further pointed out that meaningful and comprehensible input and output is quite critical for foreign language acquisition, and that a balance should be kept between them. Furthermore, EFL teachers should take into account that the EFL learning environment design is critical for suitably teaching students [4]. Cohen [25] agreed with Harmer's statements, pointing out that the ultimate goal in language learning is to interact with people. Thus, communication and interaction should be taken into consideration and the related teaching methods should be more diverse and effective. In this way, students should be allowed to have real interactive experiences, thus enabling them to master the way to learn English spontaneously [26,27].

The global market for digital English language learning is booming and there are significant revenue opportunities for suppliers. Digital English-learning-related products worldwide reached $\$ 2.8$ billion in 2015, while the five-year compound annual growth rate (CAGR) is $6.0 \%$. Revenues were predicted to surge to $\$ 3.8$ billion by 2020 [28]. It is obvious that using a digital device as a tool for English learning has become a trend. Incorporating innovative technologies, such as digital games, augmented reality, virtual reality, and language-learning apps, into education can serve to make teaching programs more diverse. From traditional one-way teaching to interactive teaching between student and teacher, multi-oriented interactions for learning have now been developed; for instance, gamification has been considered an innovative strategy for language learning and teaching.

Heil et al. [29] took the language-learning app "Memrise" as a research object, in order to carry out an examination. They found out that applying a mobile device in education may change the way of learning. Furthermore, the user feedback of the "Memrise" app for language learning was positive. Hwang et al. [30] and Norbrook and Scott [21] also proved that mobile technologies can create innovative learning environments and improve the EFL-speaking and -listening competence of elementary school students. Although mobile technologies can support language learning, Burston [31] conducted a meta-analysis to examine 291 Mobile-Assisted Language Learning (MALL) technologies and found that MALL is restricted by being too "skill-oriented," which may not allow the language learner to keep learning constantly [29]. Some studies have proved that, in the aspect of vocabulary, MALL can ensure positive-learning performance [18]. Burston [31] also pointed out that, by means of MALL, positive-learning performance-including vocabulary, reading, writing, and speaking competence-has been demonstrated [29].

It is clear that using mobile technology as a tool for language learning provides an innovative method which has a great potential. If a mobile system can create an interactive environment which is close to real world learning in English-speaking countries, it can provide an effective solution for EFL learners. In this case, the learner may be allowed to learn not only vocabulary and phrases, but also can learn more dialogue content in an interactive way. Thus, in this research, we consider the use of mobile devices with interactive technology as a tool for language learning, in order to enable EFL students to experience ubiquitous learning.

\subsection{Situational Context of Learning}

Linguistic, economic, societal, political, and life conditions, as individual student learning characteristics, as well as teaching quality, are all factors influencing the educational situations experienced by students, consequently affecting their learning performance. All of these factors contribute to learning in various ways, some subtle and indirect, making the educational experience more or less difficult for different students. Analyzing the situational context of education of both 
students and teachers is beneficial, as it can provide a more realistic view of how to facilitate the progress of students in school [32].

Harmer's [24] language-learning argument is that the languages learned by students in the class should be applied in daily life. This is a critical point, especially for EFL students, as the conversation and communication happening in situations shift from a real-life scenario to a specific situation. The situation is a crucial factor that has a strong impact on language learning and the flexibility of its application. In a proper educational situation, students may raise questions actively and spontaneously, becoming willing to express their views during the learning process. Students may be influenced unobtrusively and imperceptibly by the teaching, therefore becoming able to visually perceive objects clearer and to use a diverse vocabulary to express and work in their daily lives effectively. By the same token, Hwang et al. [30] also mentioned that the language-learning environment should be taken into account; that is, the language should be used in daily life and the learner should get used to it. Harmer [24] also considered that the teacher should create a language-learning situational environment for students to interact with other people by using language as a vehicle for daily communication. However, the learning language situation should be more realistic. Learning should be applied in real life, allowing students to connect the meanings of words to their situations. With respect to teaching situational context design, Swartz and Parks [33] proposed the method of infusion for education, by which the teacher designs suitable examples or scenarios for students to complete in the context of the original curriculum. The strategy is to help enhance critical thinking competence in students during the teaching situation. In this way, students should be put into a situational context-learning environment, thus learning by doing; as a result, students may enjoy the learning experience more and, in the meanwhile, they may come to long for knowledge as the language-learning passion is evoked through immersion in the learning experience. The learning environment influences and changes people unobtrusively and imperceptibly. In particular, the educational situation has been defined as an ever-changing environment, in which the learner may be influenced imperceptibly by specific teaching situations.

As an EFL student is generally not able to be put into an English-speaking country for learning purposes, educational situations thus could be designed by means of computer simulation, situation simulation, and game simulation. In the meantime, their learning performance should be improved through reflection and teamwork. Moreover, media could also be used as a method in situational context learning to present a specific plot, emotion, or situation consisting of certain life events, applying one or multiple forms of creative approaches, such as conversation, vocabulary, video, animation, music, drama, dance, and so on.

This situational context teaching takes place in school. Situational context teaching conducted in the classroom can create an innovative learning environment for students to effectively enhance learning effectiveness, the first job for which is classroom decoration. The teacher selects a themed situational context or infusion as a method for teaching, in order to place students into specific learning situations. Through the use of interesting interactive experiences, not only speaking and listening competence can be improved, but confidence and interest may also be spontaneously enhanced.

\subsection{AR-Assisted English Learning}

As advanced computer technology is widely used, environment simulation has been popularized for expeditionary learning. Approaches for simulation include digital technology, static or dynamic images, and experimental situations, which can be verified [34]. The best example is virtual reality, a technique that allows the user to experience impressive moments without facing any danger. In fact, many digital technologies (e.g., 3D animation, games, or AR) can provide good tools for learners to explore the future, if these digital media are combined with future-oriented thinking that consider educational goals and incorporate appropriate curriculum design [13,35,36]. More recently, AR technology using mobile devices and digital media in combination with a wide variety of partially commercially available applications for AR education, entertainment, shopping, medical, military, 
or museum applications have shown the varied and unpredictable prospects of AR. The use of AR in classrooms has been discussed by Billinghurst and Duenser [37], who mentioned the method of connecting a virtual 3D image to the real world and the perceived characteristics of virtual and real objects. Furthermore, by taking this method, 3D images can be presented from any angle by a computer, thus creating a more realistic experience. The connection of virtual scenes and the real world creates a new "reality," to a higher extent [38,39]. Khan et al. [40] presented an ARToolKit-based Interactive Writing Board (IWB) with a simple mechanism for designing confusion-free marker libraries. The board can be used to teach single characters of Arabic/Urdu to primary-level students. Their experimental results revealed that the AR system can improve the motivation and learning skills of students.

It is obvious that the combination of AR applications and mobile devices creates more creative instructional design for teaching, such as real-time spatial calculus, 3D stereoscopic presentation, interactive audio, video content, message sharing, object tagging, and intelligent agents [5]. AR allows the user to display digital information in their field-of-view through a mobile phone display and lets computer-generated objects virtually appear in the real physical world by displaying digital information in the user's field of view on the display screen. Both the physical world and digital world are rendered virtually in the same space [41]. Freedom is one of the key features of most AR-learning systems, while the side effects of AR, such as mental effort or learning anxiety, can be reduced when the design is adapted to the degree of challenge and control of students [13]. AR can support the self-directed learning of students. In a design environment oriented toward knowledge areas, such as language learning, AR for self-directed learning games allows students to enjoy learning with respect to their own ability and rhythm, thus providing solutions for possible learning problems through the creation of situational context environments [42].

Informed by the previous research, in this study, we utilize AR technology to conduct language learning using familiar surrounding contextual support; that is, the adopted AR learning methods enabled students to learn English in and make contact through a familiar context.

\subsection{Learning Motivation Theory: The ARCS Model}

The ARCS model, which integrates motivation theory and other learning related theories, was proposed by Keller, in order to encourage learning motivation in students [43]. Keller considered that, if the learning materials can attract a student's attention, their learning performance would be enhanced. Therefore, the ARCS model was proposed to set strategies for teaching program design, in order to evoke student-learning motivation and enhance their learning effectiveness and performance [5]. The ARCS motivation model supports educators to confirm the motivational needs of students and to understand the ideal strategy for curriculum design, such that student learning performance can be enhanced effectively. Thus, ARCS is an examination model that can help design teaching materials and improve learning effectiveness. By means of the ARCS model, teaching materials and content can serve as factors evoking learning motivation in students [44].

Keller [45] proposed four factors that can help teachers to evoke and retain student-learning motivation. The ARCS model can assist in curriculum design and teaching improvement. To facilitate motivation in students, the four factors must be in harmony. Along with numerous motivation theories, ARCS can strengthen teaching program designs, thus helping students to have positive learning experiences by means of heuristic teaching. In teaching design, the aspects of teaching theories, teaching activity organization, and learning goal achievements should be taken into consideration. A, $\mathrm{R}, \mathrm{C}$, and $\mathrm{S}$ are related to each other, each having an impact on the teaching effect. The teacher should take the ARCS factors into consideration, in order to enable students to learn in a positive feedback mode. If different aspects of the four factors are not to be taken into account together, the teaching may not be improved. John Keller emphasized that ARCS also has a "diagnostic" nature and a prescribing function, which means that, if learners are lacking in one or more of the ARCS aspects, there are ways to overcome these; that is, the teacher must integrate the learning design in particular ways for such learners [46]. The teacher can design a better teaching strategy for student-learning motivation by 
using information application systems or digital technology. In Table 1, the four factors proposed by Keller [45] and their definitions, as well as how they relate to the purpose of this research, are shown. Furthermore, by applying the ARCS model during the experimental process, a solution for evaluation of the four factors can be found and an examination based on the model of variations can be carried out, as explained in Table 1.

Table 1. Four elements and definitions of attention, relevance, confidence, and satisfaction (ARCS) model, following John Keller's definitions [45].

\begin{tabular}{|c|c|c|c|}
\hline Element & Definition & Variable & Purpose \\
\hline $\begin{array}{l}\text { A } \\
\text { Attitude }\end{array}$ & $\begin{array}{l}\text { Arouse the interest of } \\
\text { students, maintain the } \\
\text { attention of students, } \\
\text { and stimulate the } \\
\text { curiosity of students. }\end{array}$ & Learning attention & $\begin{array}{l}\text { 1. Whether students are } \\
\text { immersed in AR to facilitate } \\
\text { English learning. } \\
\text { 2. Does the student concentrate } \\
\text { on the learning experience with } \\
\text { AR as the teaching material? } \\
\text { 3. Observe student curiosity } \\
\text { about the subject of learning, use } \\
\text { time, and increase in } \\
\text { concentration. }\end{array}$ \\
\hline $\begin{array}{l}\mathbf{R} \\
\text { Relevance }\end{array}$ & $\begin{array}{l}\text { Students develop } \\
\text { relevant personal } \\
\text { recognition based on } \\
\text { the learning of new } \\
\text { textbooks and past } \\
\text { experience. }\end{array}$ & Learning interest & $\begin{array}{l}\text { 1. Use the learning materials } \\
\text { provided by augmented reality } \\
\text { (AR) to arouse student interest } \\
\text { in learning. } \\
\text { 2. How to make students feel } \\
\text { that this course is worth } \\
\text { studying and stimulate their } \\
\text { interest in learning? }\end{array}$ \\
\hline $\begin{array}{l}\text { C } \\
\text { Confidence }\end{array}$ & $\begin{array}{l}\text { Arouse student's } \\
\text { expectations of } \\
\text { success and positive } \\
\text { attitudes towards } \\
\text { themselves to help } \\
\text { build self-confidence. }\end{array}$ & Learning behavior & $\begin{array}{l}\text { 1. Students must use AR to } \\
\text { master the steps of learning and } \\
\text { be useful for learning. } \\
2 \text {. Student confidence and } \\
\text { concentration can be enhanced } \\
\text { by AR teaching activities. }\end{array}$ \\
\hline $\begin{array}{l}\text { S } \\
\text { Satisfaction }\end{array}$ & $\begin{array}{l}\text { Student satisfaction } \\
\text { and sense of } \\
\text { accomplishment in } \\
\text { the experience and } \\
\text { results of learning } \\
\text { will enhance their } \\
\text { self-learning } \\
\text { effectiveness. }\end{array}$ & Learning satisfaction & $\begin{array}{l}\text { 1. Use AR to allow students to } \\
\text { start self-learning, gain greater } \\
\text { satisfaction and sense of } \\
\text { accomplishment, and produce } \\
\text { lasting learning interest. }\end{array}$ \\
\hline
\end{tabular}

According to the ARCS motivation model [45], the four factors define the application purpose and help realize four constructs: (1) learning attitude; (2) learning interest (for new textbooks or materials); (3) learning behavior; and (4) learning satisfaction (from self-learning). All of these help create an appropriate teaching program by recognizing the learning motivation mechanisms of students. Thus, if a teaching program is designed to be more interesting, students will enjoy learning the related subjects, whereby student concentration can be enhanced in the class field; that is, learning interest can be spontaneously enhanced while students are learning. During learning, the meaning of educational content is to be realized, while concentration and learning interest can be enhanced further, creating an impact on learning performance. Interest is, thus, the core value for enjoyable learning [47].

Chang et al. [5] incorporated AR digital technology into an interior design teaching program and proved that students were able to come up with solutions to fix the possible problems in real 
world by teamwork during the AR educational program. They proved that learning interest and performance can be enhanced by teamwork and interactive teaching materials. Based on the related learning motivation research, Zheng et al. [44] stated that, by using ARCS as a model for improving teaching materials and content, student-learning motivation can be assessed strictly and objectively. Thus, the second purpose of this research is to use the ARCS model as a tool to examine EFL student learning concentration, interest, confidence, and satisfaction during the AR learning of new textbooks in a teaching program, in order to verify that incorporating AR technologies into situational context learning in the classroom can help to enhance student-learning performance and efficiency.

\section{Method}

\subsection{AR Experimental Teaching Design}

Mobile technologies can support language learning by providing familiar surroundings; they enable students to learn English and communicate in a familiar environment. Hwang et al. [4] proved that applying mobile techniques could improve and influence the levels of language communication of students. In junior high school English classes in Taiwan, teachers often use audio equipment or VHS tapes to assist their teaching. During the teaching experiment, the experimental group students used the HP Reveal AR app on their smartphone as an auxiliary tool for learning. By means of the AR app, the teacher could produce self-made teaching materials to help make the language-learning activities more interesting. By using the HP Reveal AR app to scan images, the experimental group students could obtain the teaching contents, which were then shown on their smartphone. The dialog contexts with 3D animations in the language-learning textbook provide a very attractive method to help students improve the listening competence and acquire relative textbook knowledge using the AR app. The HP Reveal AR technique that was used in this research to assist language learning in real-time scenarios is shown in Figure 1.

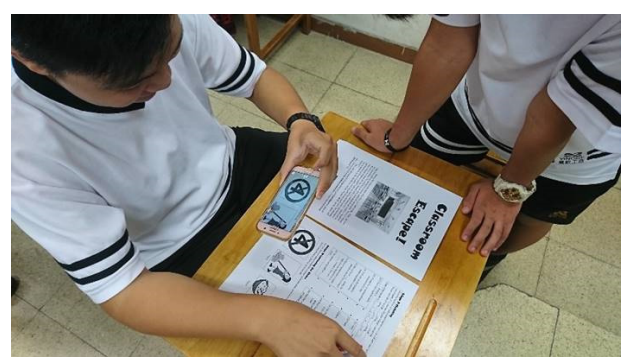

(a)

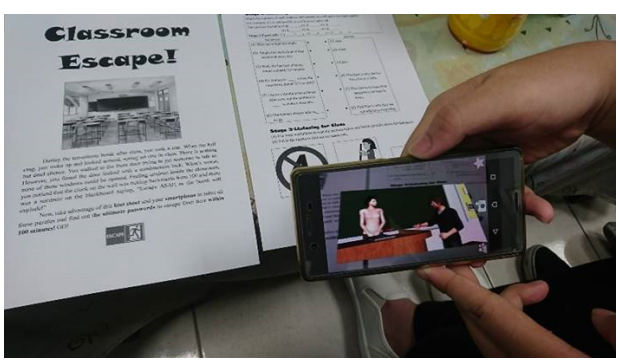

(b)

Figure 1. English-learning scenario supported by the HP Reveal app [48]: (a) Students use the AR app to align images in textbook content; and (b) the HP Reveal app displays teaching videos for specified learning topics, based on images in the textbook.

As seen in Figure 2, through the HP Reveal Aurasma studio platform, the teacher could design their own AR teaching videos and post them on the platform, where the teacher has a dedicated teaching channel. The AR teaching material could then be triggered by scanning relative images in the teaching materials. As seen in Figure 3, we took airport situational contexts as the theme and the HP Reveal AR app as the method to help the experimental group students to learn. Smartphones were used to scan airport images, in order to obtain the AR videos for airport-related English conversation content; this helped students to learn and practice airplane boarding-related conversation content, as shown in Figure 4. Using the HP Reveal app in the situational classroom, the AR videos provided interactive dialog events to help students to practice listening and acquire knowledge relating to airport departures, related to that in the textbook. In the experimental teaching group, the students used an AR technique as a tool for learning; meanwhile, the control group students were taught through traditional teaching methods in the situational classroom. After the experiment, a questionnaire was conducted in 
the experimental group students, in order to assess their learning performance, as required for the subsequent phases of research.

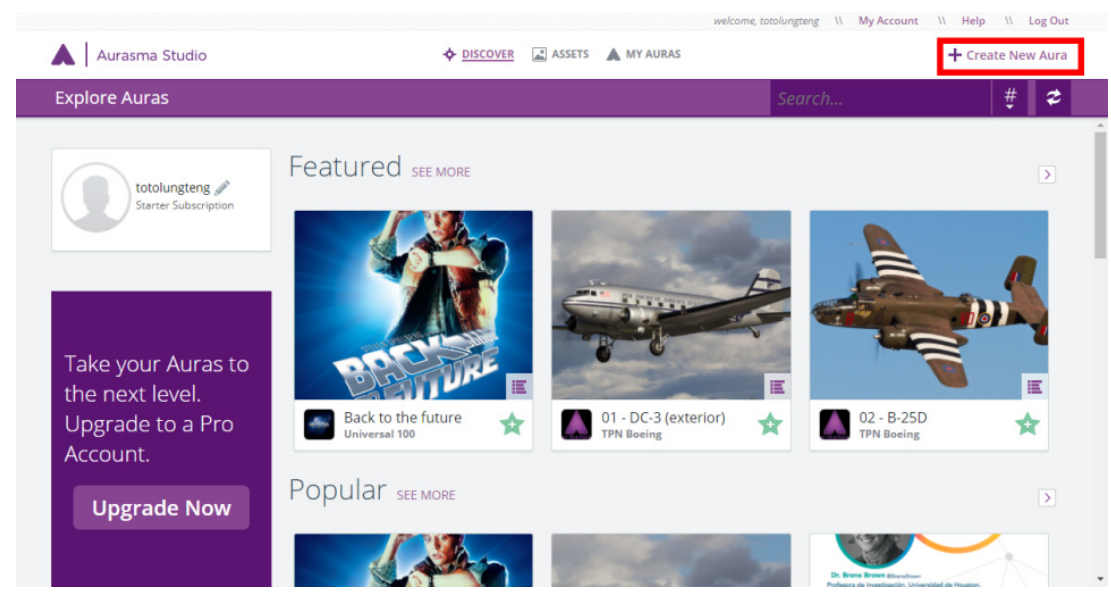

Figure 2. Aurasma studio platform, which provides the development platform for teachers to make AR-teaching videos [48].

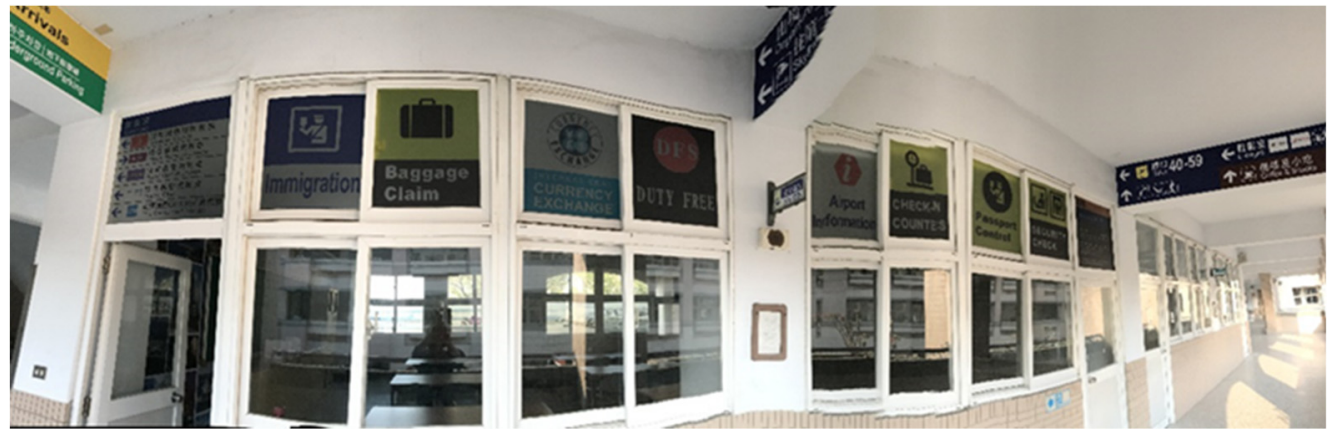

Figure 3. Situational context class for English teaching.

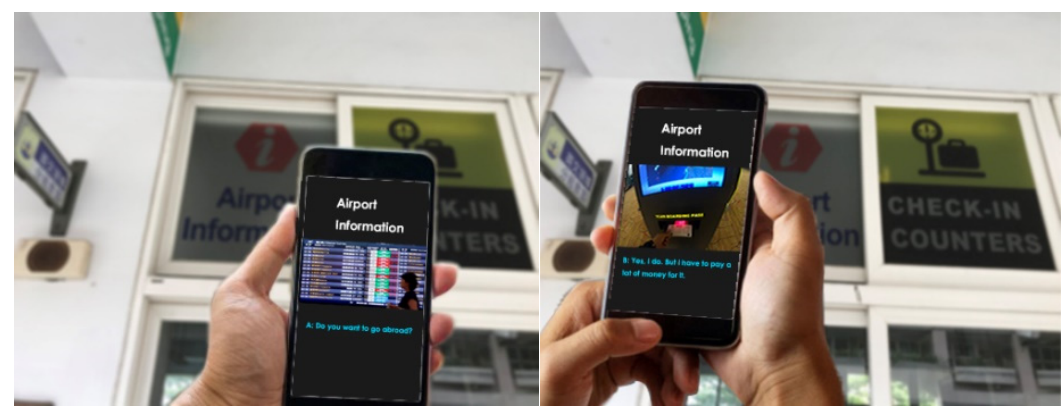

Figure 4. Experimental group students use the HP Reveal AR app to scan airport images and obtain airport situational videos for contextual learning.

Using the HP Reveal Aurasma studio platform, the teacher created eight AR-teaching videos for airport situation-related English conversation themes. In the situational context classes, students could use HP Reveal app, which was already installed on the smartphones, to scan trigger images for the eight AR teaching videos, in order to acquire knowledge about airport-related conversation, as shown in Figure 5. 


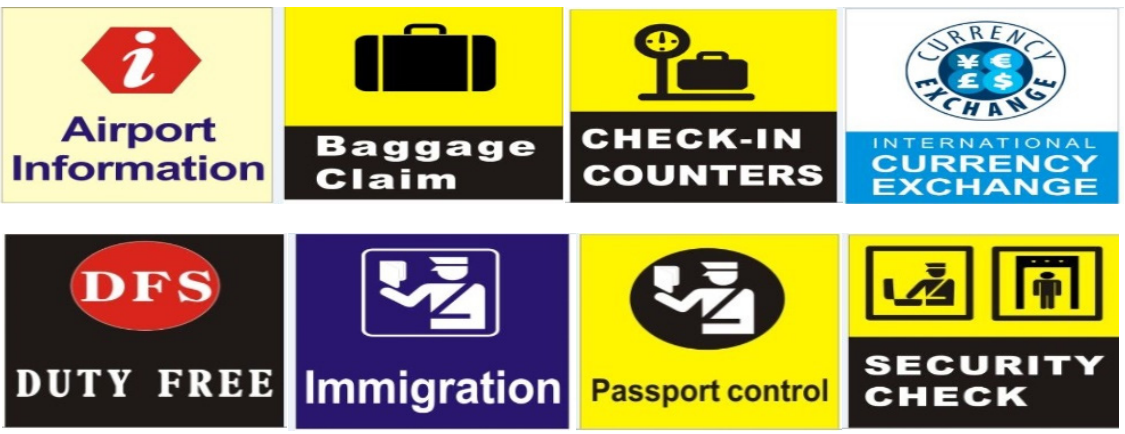

Figure 5. The eight trigger images for airport situational contexts.

\subsection{Research Methods and Approach}

In order to objectively evaluate the experimental teaching performance, we used a quasi-experimental design - that is, a non-equivalent pre-test and post-test design-as the research approach to carry out the examination, as this method (1) could draw a comparison between the experimental group and control group students; (2) used the pre-test to confirm whether the two group scores were parallel; and (3) based on the homogeneity of the two groups, it can be affirmed whether any significant change in student learning performance was the influence of the experimental teaching approach. The experimental teaching time was set by the teacher for the examination of the experimental and control groups. Students from two classes were divided into the experimental and control groups. The two groups had same teacher, same language-learning context, and same period for learning, but were taught using different teaching approaches. Applying the HP Reveal AR app was the teaching approach adopted for the experimental group, whereas the control group was taught using a traditional teaching approach; namely, using PowerPoint materials.

The overall research architecture is illustrated in Figure 6. There were three phases of experimental teaching: (1) In the first phase, a self-evaluation was conducted to confirm the variables of the two groups; (2) the two teaching approaches were processed in the second phase (the AR technique was applied in the experimental group, while the control group was taught using the traditional teaching approach); and (3) in the third phase, a post-experimental English test was conducted, in order to test whether the learning performance had been enhanced.

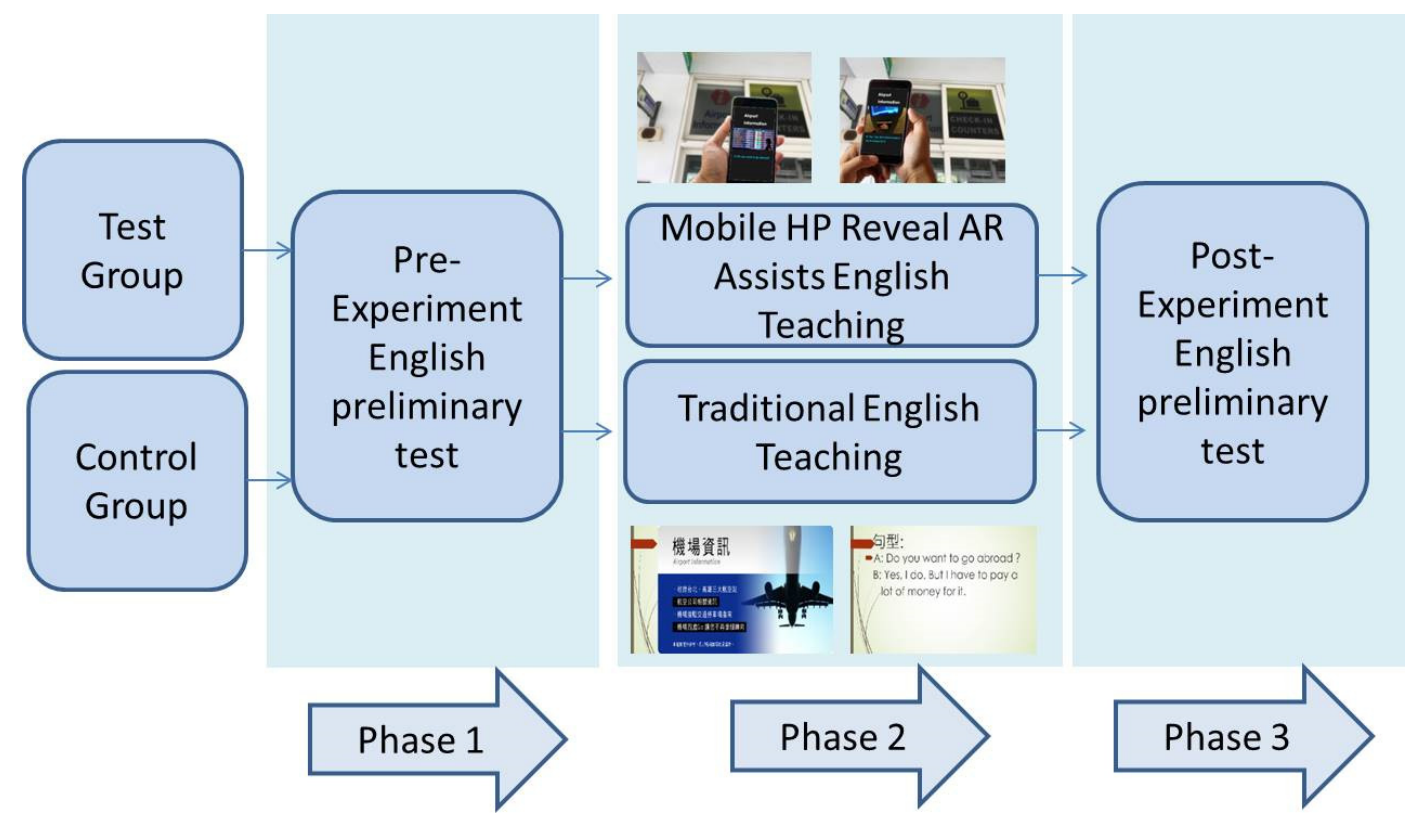

Figure 6. The three stages (phases) of our experiment. 
- In the first phase, a pre-experiment English test was carried out, based on Harmer's two indicators for checking English language proficiency [24]: language input (listening to and reading a received message) and language output (when the applied information is spoken and written). In the first week of the experimental teaching, we carried out English listening, speaking, reading, and writing tests in both groups.

- In the second phase, experimental teaching was carried out. In this stage, the experimental group received two courses of English teaching activities per week (40 min each). English lessons using the HP Reveal AR app were provided for the experimental group. The control group was taught using the traditional teaching approach. Both groups were taught in the situational context classroom.

- In the third phase, a post-experimental English test was carried out. After the 18th teaching week, the two groups (experimental group and reference group) were tested to verify the learning effect and the results of the experimental teaching method.

\subsection{Participants}

The variables of the two groups were examined, including the experimental English test results and teacher's experimental teaching program. For a reliable research finding, the two groups were taught by the same teacher, while the students experienced different teaching approaches and had different backgrounds. The pre-experiment English test and post-experiment English test were conducted for both groups of students. The learning performances of the two groups were evaluated by the same teacher.

The research subjects were 40 junior high school students from the Da-li district of Taichung City. The number of test group subjects was 21, while that of the control group was 19 . The experimental group students were taught by means of the HP Reveal AR app, while the control group students were taught using a traditional approach. During the experimental teaching, diverse themes were provided for English learning in the classroom. The learning performance associated with each theme was examined. The period of experimental teaching for the test group and control group student was from the 1st of September, 2019, when the semester began, through to the 12th of January, 2020, the end of the semester. There were 18 teaching weeks, with two classes per week. The pre-test was the first English test (week 1 of the semester) assessing the English subject in both groups. The post-test was conducted by means of writing assessment and oral answers to questions. Based on the results of the pre- and post-tests, we research and then analyzed the difference of learning performance in the two groups, in order to verify whether applying the HP Reveal AR app approach assisted language learning and had a positive impact on learning effectiveness or not.

\subsection{Questionnaire Design}

After the experimental English test, we also collected questionnaires from the experimental group students. The content of the questionnaire included whether the students were interested in AR textbooks, as well as self-reported assessments of learning concentration, learning confidence, and learning satisfaction. We then used the IBM SPSS statistical analysis software as a tool to carry out the statistical examination. After the experimental teaching, student-learning performance was assessed by the results of pre- and post-tests.

We confirmed the pre-test results of two groups by conducting independent sample $t$-test analysis, in order to determine whether the pre-test result was almost the same, and whether the post-test result of experimental group was significantly higher than that of the control group. To realize the difference between the learning performances of the two groups, we conducted a test of regression homogeneity, in order to confirm whether the variables of the pre-test results were parallel. Further, one-way ANOVA was also adopted, in order to detect whether the experimental group and the control group were homogenous or not. The pre-test results of the two groups were taken as the covariates, while the post-test results were taken as the dependent variable for learning performance examination. 
Finally, we then conducted independent sample covariate analysis to examine the significant differences between the two groups. The significance level of the statistical analysis was set as 0.05 ( $95 \%$ confidence interval). If the ANOVA result showed a significant difference in learning performance between the two groups, it can be stated that applying the HP reveal AR app to ESL teaching can have a significant impact on student-learning performance.

Harmer [24] considered the ultimate goal of language learning to be the facilitation of social interaction. Thus, the aspects of communication and interaction in the real world should be taken into consideration for the evaluation of English-learning performance for students. Thus, situations that may be experienced in the daily lives of students were used in the pre- and post-tests, including English listening, speaking, reading, and writing competence tests. Through these four English competence tests, the English-learning performance of students can be objectively evaluated. The pre-test was conducted to confirm whether the basic knowledge of the students in both groups was the same before the experimental teaching, in which the best score was 100. After the experimental teaching, the post-test was conducted (also with a best score of 100). The test items reflected the content of the courses taught by the English teacher in the semester, according to the junior high school English textbook. The post-test for learning performance evaluation was designed by the English teacher. For reliable learning performance examination, the tests were designed in four parts: listening, speaking, reading, and writing competence tests.

\section{Experimental Results}

\subsection{Evaluation of Learning Performance for Test and Control Group (Independent Sample t-Test Analysis)}

The curriculum knowledge test for English courses included the following test for the following four variables of the student's English communication skills: (1) listening, (2) speaking, (3) reading, and (4) writing. Several of these were obtained after the test. It can be seen, from the data in Table 2, that the results of the pre-test for both experimental and control groups were quite close. The post-test scores of the experimental group were higher than those of the control group. In order to understand whether the difference between the two groups reached a statistically significant level, we tested the homogeneity of the regression coefficients within the groups to confirm whether the regression lines for both groups were parallel. This indicates that both groups were comparable, and that there was no statistical difference between both groups. Thus, Table 3 provides an overall description of the statistics for both groups but does not determine the differences between both groups. This required additional analysis, which is described in the following sections of the article.

Table 2. The English knowledge of the control and experimental groups, measured before and after the English teaching conducted by the teacher. The results illustrate the overall learning performance of both groups, but further statistical evaluation is required to identify the performance of each individual test group.

\begin{tabular}{ccccccc}
\hline $\begin{array}{c}\text { Test } \\
\text { Item }\end{array}$ & Group & $\begin{array}{c}\text { Number of } \\
\text { People }\end{array}$ & $\begin{array}{c}\text { Pre-Test } \\
\text { Average }\end{array}$ & $\begin{array}{c}\text { Pre-Test } \\
\text { Standard } \\
\text { Deviation }\end{array}$ & $\begin{array}{c}\text { Post-Measurement } \\
\text { Average }\end{array}$ & $\begin{array}{c}\text { Post-Test } \\
\text { Standard } \\
\text { Deviation }\end{array}$ \\
\hline $\begin{array}{c}\text { English } \\
\text { test }\end{array}$ & $\begin{array}{c}\text { Test group } \\
\text { Control } \\
\text { group }\end{array}$ & 21 & 65.265 & 15.6122 & 78.810 & 15.9519 \\
& 19 & 53.447 & 16.5461 & 54.421 & 28.2515 \\
\hline
\end{tabular}


Table 3. Summary of the testing whether the learning ability of both groups was the same and, thus, was comparable. This test was conducted in the pre-test stage of the experiment, in order to test whether the groups were comparable and showed similar learning ability. The results show no significant difference between groups.

\begin{tabular}{ccccccc}
\hline Test Item & Source & SS & df & MS & $\begin{array}{c}F \\
\text { Value }\end{array}$ & $\begin{array}{c}\text { Variability Homogeneity } \\
\text { Test Significance }\end{array}$ \\
\hline $\begin{array}{c}\text { English test } \\
\text { in pre-test } \\
\text { stage }\end{array}$ & $\mathrm{SS}_{\mathrm{B}}$ & 1242.432 & 1 & 1242.432 & 2.807 & 0.102 \\
& $\mathrm{SS}_{\mathrm{W}}$ & 16817.343 & 38 & 442.562 & \\
\hline & $\mathrm{SS}$ & 18059.775 & 39 & & \\
& \multicolumn{6}{c}{$p>0.05}$.
\end{tabular}

\subsection{Determination of the Learning Ability of both Test- and Control Groups}

To follow-up the statistical analysis presented in Table 2, we first needed to determine whether the learning ability of each group (experimental vs. control group) was similar or the same. We tested both groups in parallel. In order to understand whether the difference between the two groups was of statistical significance, we used the homogeneity test of the regression coefficient within the group to examine whether there was any interaction between the pre-test scores of the two groups. This was conducted to confirm whether the learning abilities of both groups were the same. This was tested by verifying if the regression lines within the groups were parallel. We selected the one-way ANOVA to test whether the two groups (experimental and control group) were homogenous. The results of this verification are shown in Table 3. These tests indicate whether the learning ability of both groups was the same: The pre-test scores of both groups did not reach any significance through the homogeneity test, which satisfied the parallel test. This indicates that the pre-test of the two groups had no interaction, and that both groups were statistically independent from each other.

It can be seen, from Table 3, that the difference of experimental group and the control group in the pre-test $(F=2.807, p=0.102>0.05)$ are not significant. This satisfied the parallel check, indicating that both groups were homogenous. This was consistent with the homogeneity test of the regression coefficient within the groups. It can be determined whether the exclusion of different classes affected the pre-test results. Therefore, we further adopted a single-factor covariate analysis, where post-test scores were based on variables to include covariates for $F$-tests.

\subsection{Single Factor Covariate Analysis for Post-Test}

In the previous part of the statistical analysis, the results were used as covariates. The post-test scores of both groups were used as the variables for the effectiveness check. The independent sample single factor covariate analysis was performed. The statistical analysis used a significance level setting of 0.05 (within a 95\% confidence interval). As can be seen from Table 4, the results of the single factor covariate analysis showed that the experimental and control groups had significant differences in the post-test results $(F=11.588, p<0.001)$. These results indicate that the learning performance of test group students who were taught using AR teaching videos was better than the control group students, who were taught using a traditional teaching approach. The difference of learning effectiveness between test and control groups (i.e., research hypothesis 1) has thus been proved.

Table 4. One-way ANOVA summary table for two groups of learning outcomes.

\begin{tabular}{ccccccc}
\hline Test Item & Source & SS & df & MS & $F$ Value & Significance \\
\hline Post-test & SS $_{\mathrm{B}}$ & 5933.105 & 1 & 5933.105 & 11.588 & $0.002^{* *}$ \\
Difference between & $\mathrm{SS}_{\mathrm{W}}$ & $19,455.870$ & 38 & 511.997 & & \\
groups & $\mathrm{SS}_{\mathrm{T}}$ & $25,388.975$ & 39 & & & \\
\hline \multicolumn{7}{c}{$p<0.01}$.
\end{tabular}




\subsection{Concentration}

We conducted single factor variable analysis to examine the learning concentration for the students of the experimental group; the results are given in Table 5. The Levene standard deviation was used to describe the variable difference, where the result was $F=12.644, p<0.01$. The analysis result indicated that the experimental group students (who were taught by AR teaching videos) were more easily immersed in the situational context learning than the control group students. Regarding the test group student feedback, the AR technique-assisted language-learning approach provided them with enjoyable and interesting immersion experiences; further, the AR videos could be repeatedly played, providing an effective method for learning. The research hypothesis 1 , regarding the difference of concentration between the experimental and control group, has thus been validated.

Table 5. One-way ANOVA on student learning concentration for two groups of learning outcomes.

\begin{tabular}{|c|c|c|c|c|c|c|}
\hline Test Item & Source & SS & df & MS & $F$ Value & Significance \\
\hline learning concentration & $\mathrm{SS}_{\mathrm{B}}$ & 6.499 & 1 & 6.499 & 12.644 & $0.001^{* * *}$ \\
\hline Difference between & $\mathrm{SS}_{\mathrm{W}}$ & 19.533 & 38 & 0.514 & & \\
\hline groups & $\mathrm{SS}_{\mathrm{T}}$ & 26.032 & 39 & & & \\
\hline
\end{tabular}

\section{Evaluation of Student Motivation through Questionnaires Related to the ARCS Model}

Regarding Keller's ARCS model, there are four factors affecting the learning motivation: (1) "Attitude," which was evaluated through the aspect of concentration; (2) "relevance," which relates to students developing relevant personal recognition based on the new material provided by AR technology and past learning experiences, which was examined by the questionnaire for interest evaluation; (3) "confidence," which was evaluated by determining whether the student feedback regarding the new AR teaching materials assisting the English program was positive; and (4) "satisfaction," evaluated by determining whether students were satisfied with the use of the new AR teaching materials.

Based on the ARCS theory and the above-mentioned learning motivation-related theories, we conducted a questionnaire, in order to examine student-learning performance. Based on the definition of ARCS (see Table 1), the research questionnaire comprised of 20 questions, divided into four parts: (A) Learning attitude, with five questions regarding the student's concentration during English learning with the AR teaching materials; $(R)$ relevance, with five questions about the student's learning interest in the textbook design and AR teaching methods; (C) confidence, with five questions designed to confirm whether the student's feedback about this innovative teaching program was positive and confident; and (S) satisfaction, with five questions relating to the student's learning satisfaction relating to the AR teaching materials.

The operational definition of the four ARCS factors are clarified in the following:

(1) Learning attitude for experimental group students was evaluated using the results of the concentration questionnaire. Based on the evaluation methods produced by Csikszentmihalyi [49] and Chambers [50], "immersed experiences" was modified into the part of "concentration" for the questionnaire. Concentration can be explained as a kind of "immersed experience" that occurs during the process of language learning; that is to say, interesting and enjoyable situational contexts lead to student immersion in the learning, in which their learning attitude becomes concentrated.

(2) Learning interest can be referred to as a sort of inherent tendency, which is a part of a student's individual characteristics. In general, people spend much more time and energy to do the things that they are interested in and satisfied with [51]. Learning interest refers to the state where students are satisfied and tend to spend more time and make more effort to learn. Thus, based on the observation of student interaction and practice in the four English listening, speaking, reading, 
and writing tasks during AR-assisted English learning, learning interest was then evaluated through the research questionnaire.

(3) Learning behavior was considered, in this research, in order to confirm whether student confidence was enhanced by applying the AR technique, by determining whether student feedback on the AR-assisted English teaching program was positive. Chang et al. [5] stated that learning behavior can be used to measure whether students have improved their self-confidence after using AR. Moreover, Zheng et al. [44] pointed out that, during learning, confidence can be enhanced through the use of innovative teaching materials.

(4) Satisfaction, in this research, was considered in order to evaluate the sense of satisfaction and the sense of accomplishment gained through the experimental teaching approach. Based on the statement of Zheng et al. [44], we wanted to understand whether students agreed with the use of the new textbook AR approach, as well as their inner perception of the degree of like or dislike of AR.

In this research, we adopted a Likert five-point scale to evaluate each research construct. When filling in the questionnaire, the numbers $5,4,3,2$, or 1 were used to fill in the questionnaire, in order to indicate the student learning situation results; where 5 means "strongly agree," 4 means "agree," 3 means "neither agree nor disagree," 2 means "disagree," and 1 means "strongly disagree." If the number is higher, the recognition is better or stronger; while, if the number is lower, poor recognition is indicated. The ARCS questionnaire is shown in Appendix A.

The quantitative empirical model is shown in Figure 7.

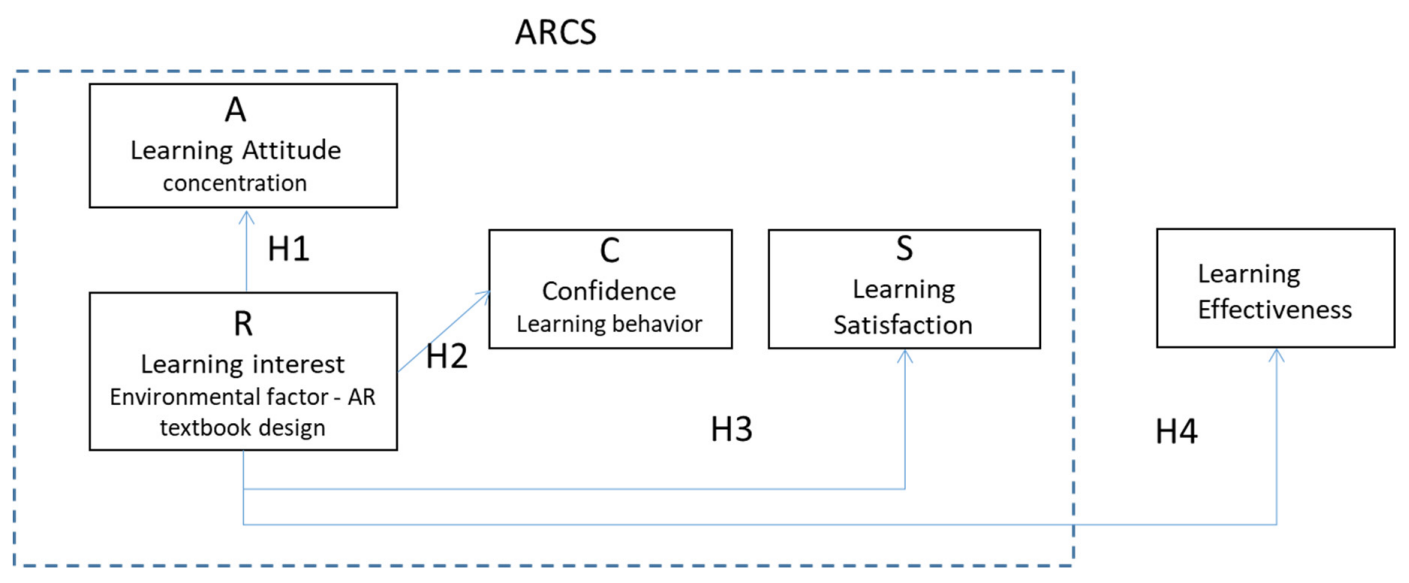

Figure 7. The ARCS learning effectiveness statistical model and the research hypotheses.

The different hypotheses underlying our research are listed below:

Hypothesis 1 (H1). The learning interest of using AR in teaching design and methods positively affects the learning attitude of students.

Hypothesis 2 (H2). The learning interest of using AR in teaching design and methods positively affects the learning behavior of students.

Hypothesis 3 (H3). The learning interest of using AR in teaching design and methods positively affects the learning satisfaction of students.

Hypothesis 4 (H4). The learning interest of using AR in teaching design and methods positively affects the Learning effectiveness of students. 


\subsection{Reliability and Validity of the Analysis}

To evaluate the reliability levels of the study, we utilized the Cronbach value, which indicates low confidence with value of $\alpha<0.35$; values between $0.35<\alpha<0.70$ indicate medium confidence; and an $\alpha$ value $>0.7$ indicates high reliability. The reliability of the results of the statistical analyses were 0.937 for the personal concentration of learning attitude; 0.949 for the learning interest for the AR teaching method; 0.873 for the confidence of learning behavior; and 0.906 for learning satisfaction. The Cronbach $\alpha$ reliability levels of our study were all above 0.7 . Thus, the overall reliability of the questionnaire in this study showed high confidence. Within the acceptable range, it has an inherent convergent consistency, indicating that it has a certain level of reliability.

As the units of the variable measurements were the same in this study (they were all based on the Likert five-point scale), their reliability can be measured by Cronbach's $\alpha$ value. In the above evaluation of the reliability, the questions in the used questionnaire showed a high homogeneity and conformed to the standard [52].

\subsection{Validity Analysis}

In this study, SPSS was used for confirmatory factor analysis (ES) to determine the facet validity of the questionnaire. The factor extraction was performed using principal component analysis (PCA) and verified by the Varimax Method of KMO and Barlett's Spherical Verification. The KMO sampling suitability was 0.727 . The square value of the spherical check was 356.129 (which is significant), indicating that the questionnaire was applicable for factor analysis. Through factor analysis, the previously set facet questions were automatically aggregated into a single facet scale.

The measurement items of each facet can be converted into a single factor facet (the feature value of each facet needs to be greater than 1), which has a certain level of validity. The decision on the number of factors was mainly based on the principle of size of the special value. The characteristic value represents the total variation that can be explained by a certain factor; the larger the value, the stronger the explanatory power of the factor.

In general, the Eigenvalues need to be greater than the one to be considered as a factor. Through principal component analysis (PCA) and the maximum revolving method, we extracted four components. The square of the rotation axis and the load showed "Learning interest" to have a value of 7.804; "Concentration of learning attitude" to have a value of 2.833; "Confidence of learning behavior" to have a value of 2.545; and "learning satisfaction" to have a value of 1.701. The Eigenvalues of the components of the square of the rotation axis and the load were all greater than one (as shown in Table 6), indicating that the questionnaire had good validity from a structural viewpoint. The cumulative value of the total factor variances explained was up to $74.416 \%$.

Table 6. Total variance explained by the factor loading.

\begin{tabular}{ccccccc}
\hline \multirow{2}{*}{$\begin{array}{c}\text { Ingredients } \\
\end{array}$} & \multicolumn{3}{c}{ Initial Eigenvalue } & \multicolumn{3}{c}{$\begin{array}{c}\text { Rotation Square Sum of Factor } \\
\text { Loadings }\end{array}$} \\
\hline & Sum & Variance $\%$ & Cumulative $\%$ & Sum & Variance\% & Cumulative\% \\
\hline Learning interest & 7.804 & 39.019 & 39.019 & 4.251 & 21.257 & 21.257 \\
Learning attitude & 2.833 & 14.167 & 53.185 & 3.789 & 18.945 & 40.202 \\
Learning behavior & 2.545 & 12.724 & 65.909 & 3.424 & 17.118 & 57.320 \\
Learning satisfaction & 1.701 & 8.507 & 74.416 & 3.419 & 17.096 & 74.416 \\
\hline
\end{tabular}

Extraction method: principal component analysis.

\subsection{Analysis of the Correlation Coefficients}

We carried out a Pearson correlation analysis to test the hypotheses of the two variables proposed in our statistical model. According to the analysis results, the resulting correlation coefficient matrix 
between the two variables was analyzed (see Table 7). Based on the empirical results in this study, it was found that:

1. There was a significant positive correlation between the "Concentration of learning attitude" in the experimental group and the "learning interest on AR teaching design," with a correlation coefficient of $0.59(* *)$;

2. The "learning interest on AR teaching design" and "confidence of learning behavior" in the experimental group were significantly positively correlated, with a correlation coefficient of $0.518\left({ }^{* *}\right)$;

3. There was a significant positive correlation between "learning interest on AR teaching design" and "learning satisfaction" in the experimental group, with a correlation coefficient of $0.568\left({ }^{* *}\right)$; and

4. "Learning interest on AR teaching design" and "learning effectiveness" in the experimental group showed a significant positive correlation, with a correlation coefficient of $0.485\left(^{(* *}\right)$.

Table 7. Correlation analysis.

\begin{tabular}{|c|c|c|c|c|c|}
\hline & $\begin{array}{l}\text { Learning } \\
\text { Attitude }\end{array}$ & $\begin{array}{l}\text { Learning } \\
\text { Interest }\end{array}$ & $\begin{array}{l}\text { Learning } \\
\text { Behavior }\end{array}$ & $\begin{array}{c}\text { Learning } \\
\text { Satisfaction }\end{array}$ & $\begin{array}{c}\text { Learning } \\
\text { Effectiveness }\end{array}$ \\
\hline $\begin{array}{l}\text { Learning attitude } \\
\text { Pearson Correlation }\end{array}$ & 1 & $0.590\left(^{* *}\right)$ & 0.306 & $0.618\left(^{* *}\right)$ & $0.822(* *)$ \\
\hline $\begin{array}{l}\text { Significance } \\
\text { (two-tailed) }\end{array}$ & & 0.005 & 0.178 & 0.003 & 0.000 \\
\hline $\begin{array}{l}\text { Learning interest } \\
\text { Pearson Correlation }\end{array}$ & $0.590(* *)$ & 1 & $0.518\left(^{*}\right)$ & $0.568\left(^{* *}\right)$ & $0.485\left(^{*}\right)$ \\
\hline $\begin{array}{l}\text { Significance } \\
\text { (two-tailed) }\end{array}$ & 0.005 & & 0.016 & 0.007 & 0.026 \\
\hline $\begin{array}{l}\text { Learning behavior } \\
\text { Pearson Correlation }\end{array}$ & 0.306 & $0.518\left(^{*}\right)$ & 1 & 0.295 & 0.320 \\
\hline $\begin{array}{l}\text { Significance } \\
\text { (two-tailed) }\end{array}$ & 0.178 & 0.016 & & 0.194 & 0.157 \\
\hline $\begin{array}{l}\text { Learning satisfaction } \\
\text { Pearson Correlation }\end{array}$ & $0.618\left(^{* *}\right)$ & $0.568\left(^{* *}\right)$ & 0.295 & 1 & $0.509\left(^{*}\right)$ \\
\hline $\begin{array}{l}\text { Significance } \\
\text { (two-tailed) }\end{array}$ & 0.003 & 0.007 & 0.194 & & 0.018 \\
\hline $\begin{array}{l}\text { Learning effectiveness } \\
\text { Pearson Correlation }\end{array}$ & $0.822\left(^{* *}\right)$ & $0.485\left(^{*}\right)$ & 0.320 & $0.509\left(^{*}\right)$ & 1 \\
\hline $\begin{array}{l}\text { Significance } \\
\text { (two-tailed) }\end{array}$ & 0.000 & 0.026 & 0.157 & 0.018 & \\
\hline
\end{tabular}

${ }^{*}$ When the significance level is 0.05 (two-tailed), the correlation is significant. ${ }^{* *}$ At a significance level of 0.001 (two-tailed), the correlation is significant. Total number of exclusions $=21$.

\subsection{Research Hypothesis Validity}

For path analysis, we used a linear regression coefficient analysis to examine the explaination of the factors of the research model (Figure 7), in order to verify the four research hypotheses.

We analyzed the causal relationships between two variables in the model, and how they directly or indirectly affected each other. The $R^{2}$ value was calculated to show the percentage of total variance which was explained by the independent variables and regression analysis model. We used SPSS as a statistical tool to analyze the results of the linear regression coefficient analysis, in order to further validate the four research hypotheses. Overall, we hoped to prove that the AR teaching design can significantly assist English teacher and enhance concentration, confidence, satisfaction, and learning effectiveness in EFL students.

Next, we tested whether the direct influence of the independent variable (learning interest using AR) on the dependent variable existed and was significant. The $\beta$ value was obtained after making sure, 
during the path analysis, that it was the weighted value that the independent variable significantly affected the dependent variable. Moreover, the adjusted $R^{2}$ value was used as the explanatory indicator of each dependent variable of the research model. The path analysis of the four research hypotheses is explained in the following.

- Function 1: Learning attitude $=f\{$ Learning interest $\}$-According to the ARCS theory proposed by Keller, the factors influencing learning interest are teaching methods and textbook design in environmental factors (referred to as "textbook design" in this study). Among these, it was found that the "Learning interest" of AR textbook design positively affected the factor of "Learning attitude" in the experimental group students $\left(\beta=0.59, p=0.005<0.05, R^{2}=0.314\right)$. The explanatory power was $31.4 \%$, reaching a significant level; thus, $\mathrm{H} 1$ is valid.

- Function 2: Learning behavior $=f$ \{Learning interest $\}$-After statistical regression, "Learning interest" was one of the factors affecting the factor of "Learning behavior" $(\beta=0.518$, $p=0.016<0.05, R^{2}=0.23$ ). It can be seen that the Learning interest of AR textbook design positively affected the factor of "learning behavior" in the experimental group students, reaching a significant level. Thus, $\mathrm{H} 2$ is valid. It can be seen that the students in the experimental group were affected by the AR teaching design, in terms of learning behavior.

- Function 3: Learning satisfaction $=f\{$ Learning interest $\}$-After statistical regression, "Learning interest" was one of the factors affecting the learning satisfaction $(\beta=0.555$, $p=0.009<0.05, R^{2}=0.272$ ). It can be seen that the learning interest of AR textbook design positively affected the factor of "learning satisfaction" in the experimental group students, reaching a significant level. Thus, $\mathrm{H} 3$ is valid. It can be seen that the learning satisfaction of the experimental group students was influenced by the interest in the AR textbook design.

- Function 4: Learning effectiveness $=f$ \{Learning interest $\}$-After statistical regression, "teaching material design" was one of the factors affecting learning outcomes $(\beta=0.445$, $\left.p=0.043<0.05, R^{2}=0.156\right)$. It can be seen that the learning interest of AR textbook design positively affected the factor of "learning effectiveness" in the experimental group students, reaching a significant level. Thus, $\mathrm{H} 4$ is valid. It can be seen that the learning outcomes of the experimental group students were influenced by their interest in the AR textbook design.

Figure 8 shows the overall regression analysis of this study. The results of the regression analysis are shown using arrows between the different factors. If the regression analysis following an arrow was significant, the normalized coefficient data have an asterisk $\left(^{*}\right)$. In the statistical sense, the $95 \%$ level is usually used to calculate the confidence interval. The $95 \%$ significance is standard when proving a reliable result, which means there is a $95 \%$ chance of having a reliable result which reflects the real data. The 95\% reliable standard and p-value have similar meaning in the statistical verification of significance. Such significance indicates that a causal relationship has a direct effect, which can be confirmed by the presence of a letter. Otherwise, if the normalized coefficient data are not significant, there will be no asterisk (indicating that there is no direct effect) and the arrow segment does not exist.

The linear regression coefficient analysis result can be used to examine the learning performance of the students. When adopting the AR technique in situational context teaching, the learning interest of students has a great impact on their learning attitude and can improve their concentration. This influence was explained up to 0.383 . Learning interest also affects student confidence; this influence was explained up to 0.23 . As for satisfaction, this was also influenced by learning interest and the influence was explained up to 0.272 . Finally, the variable of learning effectiveness was explained up to 0.156 . The results of the above analysis confirm "learning interest" as a single independent factor. We know that student-learning effectiveness is influenced by multiple factors; for example, the environment in the situational context classrooms, teaching program design, interactions with other students, individual learning ability, and individual learning style can all have impacts on student-learning effectiveness. The purpose of this research was to verify that applying an AR technique in an experimental teaching approach can lead to a significantly positive impact on learning 
motivation. To this end, our four research hypotheses were validated by means of path and linear regression analyses.

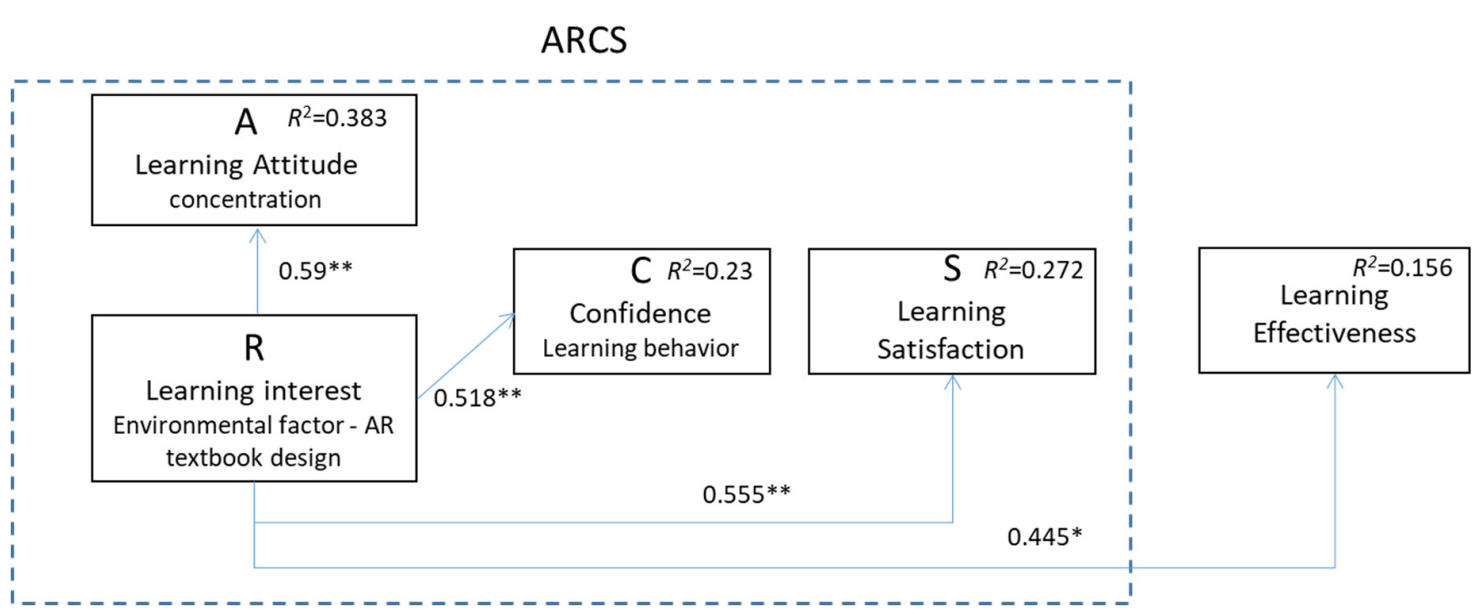

Figure 8. ARCS model path analysis results of test group learning performance. ${ }^{*} p<0.05,{ }^{* *} p<0.01$.

\section{Discussion}

In this research, we conducted a statistical analysis to examine the differences between two groups: An experimental group of students, taught using AR teaching materials; and a control group of students, who were taught by PowerPoint in a traditional teaching approach. In addition to performing reliability and efficiency verification, correlation coefficient and linear regression coefficient analyses were conducted to examine the research hypotheses. The research findings confirmed that learning interest created by AR learning can have a positive impact on the concentration, satisfaction, confidence, and learning effectiveness of ESL students.

In the following, we compile the key findings of our statistical analyses and experiments, as well as comparing them to our research hypothesis:

1. The learning interest of students created in the process of AR-assisted English textbook learning was as expected before and after conducting the research. Thus, Research Hypothesis 1 was confirmed and accepted (as mentioned in Section 5.4); that is, learning interest created by AR teaching materials can have a positive influence on student concentration. In this research, we used airport themes for situational context teaching. In the AR teaching design, the students used smartphones to scan trigger images of airport situational contexts in the classroom and obtained airport-related real-life scenario conversation videos for communication learning. The key point is still whether AR-based teaching content can meet the needs of real-world conversation. Moreover, we have proved that innovative technology can change the teaching approach, as well as the learning style. E-learning using AR is the best example, which has allowed students freedom and convenience by learning using their mobile devices; thus, students can easily become immersed in the situational context E-learning program.

2. Game elements in AR techniques have been considered as a research topic in numerous AR studies $[13,35,36]$. Unlike the previous integration of AR into teaching studies, we considered the learning interest created by AR situational context teaching materials as the independent variable, in order to examine the difference between two groups. The main reason for this is that we wanted to understand the influence of using AR to establish a learning environment on the learning effectiveness. Based on the results of linear regression coefficient analysis, we can conclude that AR-assisted English learning can have a positive impact on learning behavior, learning satisfaction, and learning effectiveness and that, during real-life scenario situational context teaching, student confidence and concentration can be enhanced. Thus, Research Hypothesis 2 was verified. Student satisfaction can be enhanced by use of an AR-assisted 
interactive English-speaking and listening conversation approach in a situational context teaching classroom. Thus, Hypothesis 3 was validated. Using the AR technique, the English teaching materials can be repeatedly played, thus providing an effective way for students to spontaneously learn and to enhance their English listening, speaking, reading, and writing competence. Thus, AR-assisted English learning can help to enhance learning performance and, so, Hypothesis 4 was also validated. The explanatory value of learning interest in terms of learning effectiveness was interpreted as $R^{2}=0.156$. Because of the short-term (18 week) experimental teaching, the $R^{2}$ value was low. Under this time limit, only three themes of situational teaching can be experienced, at most.

3. The ARCS model has been emphasized and applied by numerous researchers for the study of learning effectiveness and learning motivation [30,44,53-55]. The ARCS learning motivation theory emphasizes individual characteristics and learning environments, which may affect a student's willingness to make effort in learning and create a positive feedback cycle of learning effectiveness for the student. Stimulating interest in learning through instructional design is the key to providing an appropriate and interesting learning environment for students. Under this environment, students are likely to spontaneously make effort to learn, as their confidence is enhanced. This is the learning value emphasized by the ARCS learning motivation theory. Compared with students who have no interest in learning when taught using the traditional teaching approaches, the students who were taught using AR teaching materials may show better learning performance. Thus, among all the variables in ARCS, we took the AR teaching materials program design as the single-factor independent variable for analysis. However, in terms of AR-assisted English situational context classroom experimental teaching, Keller's ARCS theory is in harmony with the findings of this research. We proved that Keller's ARCS theory can be combined with the application of AR technology and applied to teaching practice in English situational classrooms.

\section{Conclusions}

Brisk et al. [32] and Harmer [24] put emphasis on the importance of situational environments for language learning. Shifting the educational environment from a real-life scenario to a specific situation is considered quite important for EFL students to learn English conversation and communication. Based on the above arguments, situational English-learning environments are considered crucial for language learning in Taiwan. Since 2006, English situational context classrooms have been built in Taoyuan County, Taiwan, in which airport, restaurant, hotel, train station, bank, post office, shopping mall, hospital, library, living room, and traffic themes can be experienced for the purpose of learning English. After that, junior high schools in Taipei City, New Taipei City, and Taichung City, have also established English situational context classrooms. In English situational context classrooms, the teacher leads students to experience real-life scenarios, in order to improve their situational conversation and narrative practice.

As mentioned in Section 2.3, Feiner [38] and Mackay [39] have stated that AR techniques can connect the virtual world to real world, thus being able to create more authentic English situational context environments with more interaction capacity. In this research, we used the HP Reveal app to design AR teaching materials for students to have specific contextual topics for English learning. Differing from traditional learning approaches, by applying AR techniques to English situational context classrooms, students are free to learn any English themes using widely available smartphone devices. Furthermore, AR technique-assisted learning is suitable to individual learning abilities and individual learning progress. Throughout an English-learning program over a whole semester, one of the researchers was also the teacher, who carried out the examination of student learning situations and collected the research questionnaire. The focus of our research was to verify whether AR techniques can have a positive impact on the situational context learning experience for EFL students; to this end, we used Keller's ARCS model to validate our research hypotheses. 
In short, we can conclude that (1) AR-assisted English teaching programs can help enhance the concentration of ESL students in English-speaking practice; (2) AR real-life scenarios can enhance the motivation of EFL students and increase their willingness to learn English by themselves; (3) applying AR techniques in situational context English classrooms can enhance the satisfaction of EFL students; and (4) AR-assisted English teaching can help students to learn English spontaneously and, therefore, their learning experience and learning effectiveness can be improved. The contribution of this research is taking the ARCS motivation model and incorporating digital technology (e.g., AR techniques) into English teaching in an objective and rigorous method, in order to analyze and examine the change in English-learning performance of EFL students.

Limitations: The effectiveness of language learning requires continuous practice to accumulate performance in language communication skills. Our experimental teaching of this research only lasted one semester. Furthermore, the AR teaching content required the teachers to prepare a long time for curriculum design and system development. After one semester, the experimental group students only experienced three contextual teaching environments. Therefore, the relevance and influence of student interest in AR textbooks and their learning effectiveness are significant, but require further improvement.

Author Contributions: Conceptualization, C.-N.C. and C.-L.L.; methodology, Y.-S.C. and C.-L.L.; software, C.-L.L.; validation, Y.-S.C., C.-N.C., and C.-L.L.; formal analysis, Y.-S.C. and C.-L.L.; investigation, C.-L.L.; resources, C.-N.C.; data curation, Y.-S.C. and C.-L.L.; writing - original draft preparation, Y.-S.C. and C.-L.L.; writing-review and editing, Y.-S.C.; visualization, Y.-S.C. and C.-L.L.; supervision, C.-N.C.; All authors have read and agreed to the published version of the manuscript.

Funding: This research received no external funding.

Conflicts of Interest: The authors declare no conflict of interest.

\section{Appendix A}

A: Learning attitude for MAR materials design

1. I can immerse in the English listening practice situation by using AR.

2. I can immerse in the English-speaking practice situation by using AR.

3. I can immerse in the English reading practice situation by using AR.

4. I can immerse in the English writing practice situation by using AR.

5. I can be immersed in the English-learning situation provided by using AR.

R: Learning interest by AR

1. I think that learning English by using AR is interesting in the listening practice.

2. I think that learning English by using AR is interesting in the speaking practice.

3. I think that learning English by using AR is interesting in the reading practice.

4. I think that learning English by using AR is interesting in the writing practice.

5. I think that learning English by using AR is interesting in this semester.

Learning behavioral for confidence

1. I have confidence in learning the English listening practice.

2. I have confidence in learning the English-speaking practice.

3. I have confidence in learning the English reading practice.

4. I have confidence in learning the English writing practice.

5. I have confidence in learning the English course in this semester.

Learning satisfaction

1. I am satisfied with learning the English listening practice.

2. I am satisfied with learning the English-speaking practice.

3. I am satisfied with learning the English reading practice. 
4. I am satisfied with learning the English writing practice.

5. I am satisfied with learning the English course in this semester.

\section{References}

1. Van Diggelen, M.R.; Bruns, M. Towards a vision for industrial design education. In Proceedings of the 43rd SEFI Annual Conference, Orléans, France, 29 June-2 July 2015.

2. Clark, R.E. Reconsidering research on learning from media. Rev. Educ. Res. 1983, 53, 445-459. [CrossRef]

3. Catrambone, R.; Seay, F.A. Using animations to help students learn computer algorithms. Human Factors 2002, 44, 495-511. [CrossRef] [PubMed]

4. Hwang, W.; Shih, T.; Ma, Z.; Shadiev, R.; Chen, S. Evaluating listening and speaking skills in a mobile game-based learning environment with situational contexts. Comput. Assist. Lang. Learn. 2015, 29, 639-657. [CrossRef]

5. Chang, Y.-S.; Hu, K.-J.; Chiang, C.-W.; Lugmayr, A. Applying Mobile Augmented Reality (AR) to Teach Interior Design Students in Layout Plans: Evaluation of Learning Effectiveness Based on the ARCS Model of Learning Motivation Theory. Sensors 2020, 20, 105. [CrossRef] [PubMed]

6. Shadiev, R.; Yang, M. Review of Studies on Technology-Enhanced Language Learning and Teaching. Sustainability 2020, 12, 524. [CrossRef]

7. Shadiev, R.; Sun, A.; Huang, Y.M. A study of the facilitation of cross-cultural understanding and intercultural sensitivity using speech-enabled language translation technology. Br. J. Educ. Technol. 2019, 50, 1415-1433. [CrossRef]

8. Golonka, E.M.; Bowles, A.R.; Frank, V.M.; Richardson, D.L.; Freynik, S. Technologies for foreign language learning: A review of technology types and their effectiveness. Comput. Assist. Lang. Learn. 2014, 27, 70-105. [CrossRef]

9. Cheon, H. The viability of computer mediated communication in the Korean secondary EFL classroom. Asian EFL J. 2003, 5, 1-61.

10. Shadiev, R.; Hwang, W.Y.; Huang, Y.M.; Liu, C.J. Investigating applications of speech totext recognition for face to face seminar to assist learning of non-native English participants. Technol. Pedagog. Educ. 2016. [CrossRef]

11. Tsou, W. Improving speaking skills through instruction in oral classroom participation. Foreign Lang. Ann. 2005, 38, 46-55. [CrossRef]

12. Crescente, M.L.; Lee, D. Critical issues of m-learning: Design models, adoption processes, and future trends. J. Chinese Inst. Ind. Eng. 2011, 28, 111-123. [CrossRef]

13. Hsu, T.C. Learning English with augmented reality: Do learning styles matter? Comput. Educ. 2017, 106, 137-149. [CrossRef]

14. Ho, S.C.; Hsieh, S.W.; Sun, P.C.; Chen, C.M. To activate English learning: Listen and speak in real life context with an AR featured u-learning system. J. Educ. Technol. Soc. 2017, 20, 176-187.

15. Munday, P. The Case for Using Duolingo as Part of the Language Classroom Experience. Rev. Iberoam. Educ. Distancia 2016, 19, 83-101. Available online: https://pdfs.semanticscholar.org/bb70/ 17902eb1bebb83aba5f5ad8637af7846a802.pdf (accessed on 12 June 2020). [CrossRef]

16. GSMA. The Mobile Economy 2019. Available online: https://www.gsmaintelligence.com/research/?file= b9a6e6202ee1d5f787cfebb95d3639c5\&download (accessed on 12 June 2020).

17. Taiwan Communication Survey (TCS). The Survey on Mobile Phone Usage Habits of Taiwanese. 2019. Available online: http://www.crctaiwan.nctu.edu.tw/epaper/\%E7\%AC\%AC90\%E6\%9C\%9F20190815.htm (accessed on 15 June 2020).

18. Duman, G.; Orhon, G.; Gedik, N. Research trends in mobile assisted language learning from 2000 to 2012. ReCALL 2015, 27, 197-216. [CrossRef]

19. Griva, E.; Semoglou, K.; Geladari, A. Early foreign language learning: Implementation of a project in a game-based context. Procedia Soc. Behav. Sci. 2010, 2, 3700-3705. [CrossRef]

20. Kinzie, M.B.; Joseph, D.R. Gender differences in game activity preferences of middle school children: Implications for educational game design. Educ. Technol. Res. Dev. 2008, 56, 643-663. [CrossRef] 
21. Norbrook, H.; Scott, P. Motivation in mobile modern foreign language learning. In MLEARN: Learning with Mobile Devices; Attewell, J., Da Bormida, G., Sharples, M., Savill-Smith, C., Eds.; Learning and Skills Development Agency: London, UK, 2003; pp. 50-51.

22. Liu, T.Y.; Chu, Y.L. Using ubiquitous games in an English listening and speaking course: Impact on learning outcomes and motivation. Comput. Educ. 2010, 55, 630-643. [CrossRef]

23. Folmar, D. Game It Up: Using Gamification to Incentivize Your Library; Rowman \& Littlefield: Maryland, MD, USA, 2015; p. 5.

24. Harmer, J. The Practice of English Language Teaching; Longman: London, UK, 2007; p. 1.

25. Cohen, A.D. Comprehensible pragmatics: Where input and output come together. In New Perspectives on Individual Differences in Language Learning and Teaching; Pawlak, M., Ed.; Springer: Berlin/Heidelberg, Germany, 2012; pp. 249-261.

26. Lightbown, P.M.; Spada, N. How Languages are Learned; Oxford University Press: Oxford, UK, 2006.

27. Celce-Murcia, M. Rethinking the role of communicative competence in language teaching. In Intercultural Language Use and Language Learning; Soler, E.A., Jorda, M.P.S., Eds.; Springer: Dordrecht, The Netherlands, 2007; pp. 41-57.

28. Ambient Insight. The 2016-2021 Worldwide Self-paced eLearning Market: Global eLearning Market in Steep Decline. 2017. Available online: https:/uhlberg-advisory.de/wp-content/uploads/2017/06/AmbientInsight_ The-2016-2021_Worldwide_Self-paced-eLearning_Market.pdf (accessed on 12 June 2020).

29. Heil, C.R.; Wu, J.S.; Lee, J.J. A review of mobile language learning applications: Trends, challenges and opportunities. EuroCALL Rev. 2016, 24, 23-27. [CrossRef]

30. Hwang, W.Y.; Chen, H.S.L.; Shadiev, R.; Huang, Y.M.; Chen, C.Y. Improving English as a foreign language writing in elementary schools using mobile devices in familiar situational contexts. Comput. Assist. Lang. Learn. 2014, 27, 359-378. [CrossRef]

31. Burston, J. Twenty years of MALL project implementation: A meta-analysis of learning outcomes. $\operatorname{Re} C A L L$ 2015, 27, 4. [CrossRef]

32. Brisk, M.; Burgos, A.; Hamerla, S. A Window into the World of Bilingual Learners. In Situational Context of Education; Routledge: Abinden, UK, 2003; pp. 1-261. [CrossRef]

33. Swartz, R.J.; Parks, S. Infusing the Teaching of Critical and Creative Thinking into Content Instruction; Critical Thinking \& Software: Pacific Grove, CA, USA, 1994.

34. MIT. Introducing TEAL (Technology-Enabled Active Learning). 2005. Available online: http://icampus.mit. edu/teal/ (accessed on 13 June 2020).

35. Schrier, K. Using augmented reality games to teach 21st century skills. In ACM SIGGRAPH 2006 Educators Program (SIGGRAPH '06); Association for Computing Machinery: New York, NY, USA, 2006. [CrossRef]

36. Cai, S.; Wang, X.; Chiang, F.-K. A case study of augmented reality simulation system application in a chemistry course. Comput. Human Behav. 2014, 37, 31-40. [CrossRef]

37. Billinghurst, M.; Duenser, A. Augmented reality in the classroom. Computer 2012, 45, 56-63. [CrossRef]

38. Feiner, S.K. Augmented reality: A new way of seeing. Sci. Am. 2002, 286, 48-55. [CrossRef]

39. Mackay, W.E. Augmenting reality: A new paradigm for interacting with computers. La Rech. 1996, $33,284$.

40. Khan, D.; Rehman, I.; Ullah, S.; Ahmad, W.; Cheng, Z.; Jabeen, G.; Kato, H. A Low-Cost Interactive Writing Board for Primary Education using Distinct Augmented Reality Markers. Sustainability 2019, 11, 5720. [CrossRef]

41. Milgram, P.; Takemura, H.; Utsumi, A.; Kishimo, F. Augmented Reality: A Class of Displays on the RealityVirtual Continuum. In Proceedings of the Telemanipulator and Telepresence Technologies, Boston, MA, USA, 31 October-1 November 1994; pp. 2334-2351.

42. Fischer, G.; Scharff, E. Learning technologies in support of self-directed learning. J. Interact. Media Educ. 1998. [CrossRef]

43. Keller, J.M. Motivational design of instruction. In Instructional Design Theories and Models: An Overview of Their Current Status; Reigeluth, C.M., Ed.; Lawrence Erlbaum Associates: Hillsdale, NJ, USA, 1983; pp. 386-434.

44. Zheng, H.-W.; Chen, S.-T.; Fan, G.-G. Study on the Evaluation of Students' Learning Movtivation Indicators from Using Facebook Communities-Talking the Culture Thinking and Creation of Digital Photography as an Example. Int. J. Digit. Media Des. 2019, 11, 17-32.

45. Keller, J.M. Development and use of the ARCS model of instructional design. J. Instr. Dev. 1987, 10, 2-10. [CrossRef] 
46. Keller, J.M. Five fundamental requirements for motivation and volition in technology-assisted distributed learning environments. Rev. Inter Ação 2010, 35, 305-322. [CrossRef]

47. Kintsch, W. Learning from text, levels of comprehension, or: Why anyone would read a story anyway. Poetics 1980, 9, 87-98. [CrossRef]

48. HP Reveal. Available online: https://dgs.lungteng.com.tw/tf/tool.html?id=2 (accessed on 13 June 2020).

49. Csikszentmihalyi, M. Beyond Boredom and Anxiety; Jossey-Bass: San Francisco, CA, USA, 1975.

50. Chambers, A. The Reading Environment; Thimble Press: Stroud, UK, 1991.

51. Krapp, A.; Hidi, S.; Renninger, K. Interest, learning, and development. In The Role of Interest in Learning and Development; Psychology Press: East Sussex, UK, 1992; pp. 3-25.

52. Nunnally, J.C. Psychometric Theory; McGraw-Hill Series in Psychology; McGraw-Hill: New York, NY, USA, 1978; ISBN 9780070474659.

53. Keller, J.M.; Suzuki, K. Use of ARCS Motivation Model in Courseware Design in Instructional Designs for Microcomputer Courseware; Erlbaum: Hillsdale, NJ, USA, 1998; pp. 34-40.

54. Taran, C.N. Motivation techniques in eLearning. In Proceedings of the 5th IEEE International Conference on Advanced Learning Technologies, Kaohsiung, Taiwan, 5-8 July 2005; pp. 617-619. [CrossRef]

55. Amin, I.M.; Isa, W.A.; Sidek, A.F.; Ibrahim, H.; Zulkipli, Z.A. Investigating motivational dimensions for e-learning: A case study of dental students. In Proceedings of the 2013 IEEE Business Engineering and Industrial Applications Colloquium (BEIAC), Langkawi, Malaysia, 7-9 April 2013; pp. 214-218.

Publisher's Note: MDPI stays neutral with regard to jurisdictional claims in published maps and institutional affiliations. 